\title{
Reconsideration of Yoush Mazandaran Capabilities to Develop Tourism with a Glance at Local Features of the Area
}

\author{
Salma Shafaee ${ }^{1, ~ *}$, Hoseinali Jamshidi ${ }^{1}$, Ali Dashti Shafiee ${ }^{2}$ \\ ${ }^{1}$ Architecture Department, Islamic Azad University - Savadkooh Branch, Savadkooh, Iran \\ ${ }^{2}$ Architecture Department, Shomal University of Amol, Amol, Iran
}

Email address:

salma_14483@yahoo.com (S. Shafaee), doctorjamshidi.architect@gmail.com (H. Jamshidi), ali_shafii_7@yahoo.com (A. D. Shafiee)

\section{To cite this article:}

Salma Shafaee, Hoseinali Jamshidi, Ali Dashti Shafiee. Reconsideration of Yoush Mazandaran Capabilities to Develop Tourism with a Glance at Local Features of the Area. International Journal of Science, Technology and Society. Special Issue: Research and Practice in Architecture and Urban Studies in Developing Countries. Vol. 3, No. 2-1, 2015, pp. 75-80. doi: 10.11648/j.ijsts.s.2015030201.25

\begin{abstract}
Nowadays, due to city irregularities, disconnection of current architecture with the culture and climate of each region, and radical dependency to the values of western fashion have drawn their concepts to the rural houses, regions replete with faith, culture and hidden Persian culture. Therefore a village from Mazandaran province was chosen which in addition to natural charm and pristine and untouched nature, several thousand-year history and rich cultural attractions, also has a lot of capabilities in rural tourism development - a fundamental topic in tourism. This research attempts to turn the village into a cultural, tourism center to make a sustainable cultural and tourism development with a glance at related local features. This is a historical-interpretative article and the data gathering is based on documentations. Firstly we will mention concepts related to rural tourism and sustainability, then briefly review the existing potentials in villages and finally present solutions in order to deliver the preferred objectives, may they work.
\end{abstract}

Keywords: Sustainability, Sustainable Development, Yoush Village, Rural Tourism

\section{Introduction}

With the ever-increasing expansion of rural migrations and reduced rural family income, the urgent need of an alternative for agriculture in rural areas is felt. In order to create a sustainable rural development that provides villagers with sustainable livelihood, considering the tourism industry in developing rural regions can be effective in proper utilization of human and natural resources also making the economic growth, agricultural sector promotion and production of local hand crafts possible and take a step in optimizing the environmental conditions and stewardship of the cultural heritage of indigenous and local customs, in the villages. It must be emphasized that the basics of rural tourism is the combination of rural environment, farm activities and specific cultures available in the village in order to provide the fun and variety for tourists and create an opportunity for local people to earn more salary, create employment and familiarity with different cultures and make contact with people outside of their village [9]. Creating this opportunity needs to be done without environmental degradation.
Yoush village, located between the central Alborz Mountains, surrounded by the midst of heights, has its own climate making it to show its beauty differently in each season. The village has a lot of springs, oz roaring river, plentiful trees of plums, apples, pears, etc. Weather conditions and pristine nature of the area is still intact due to its rough paths, well kept the village structure, and also historical factors, ancient traditions and customs can lead to tourism industry development in the area.

In this study, tried to have the following questions answered:

1. Are the existing potentials in the Yoush village suitable to attract tourists?

2. Is the cultural-tourism facility well enough for the needs of tourists and indigenous people?

3. Are we able to promote the tourism industry into a sustainable development through reinforcing the existing potentials in Yoush village?

At first, we will discuss the concept of sustainability, rural 
tourism and sustainability in the rural tourism, then a few potentials of Yoush village that are capable of boosting will be reviewed, also some examples of areas with similar architecture and native patterns will be discussed and solutions in order to advance Yoush village along with principles of sustainable development and tourist attraction will be given.

\subsection{Rural Tourism}

Traveling is in human nature. Human beings are created in a way that needs to travel. It is a vital need. The first human begin who began traveling did not know about its outcomes and his paths. He just went by instinct, because he was a human being, started going with no clear destination[2] says tourism nowadays is a very complex and developed business; and new tourists are exact and clever people. Traveling is not only about visiting a place but learning about other people's culture and lifestyles. [3] says the social awareness of the matter that tourism is a considerable source of income for a country economy made the concept of tourism so vast in different economic, social and cultural fields and to be taken account as an industry, [10] furthermore many of the planners and policy makers of development also put tourism industry as the main pillar of sustainable development. In this regard, the development of rural areas and expansion of tourism with the title of rural tourism is an important part of the industry. Rural tourism can be a solution to stop poverty, employment, healthcare, security and etc. A trick to grow the economical power, a capability booster to live in remote areas, community revitalization stimulant and an improvement in the living condition of rural communities [16] that upon an appropriate plan and management can create or stimulate a developed process to achieve sustainability in rural regions and sustainability of local communities in all specifications.

\subsection{Architecture and Sustainability}

What is meant by the current meaning of sustainability is what can be sustainable in the future.

There are three principles to get sustainable:

First principle is becoming one with background; it is not merely limited to nature or other single elements but meaning the society, political, economical, cultural, educational, geographical and historical backgrounds. So becoming one with environmental factors in the best way possible can be taken into account as principle to achieve sustainability.

Second principle is independency or lack of dependency; a sustainable system needs to repair and regulate itself and requires no external element to get help for example; all ecosystems in the nature.

Third principle is newness and freshness of a work; meaning the ability to repair and get refreshed. [13]

At last we need to comply with the sustainability criteria, acting to which is only possible with participation of the indigenous people.

\section{Tourist Attraction Indicators in a Village}

Local people culture which includes all the things that make them different from other communities, like structural architecture, dialect, dressing, music and rituals, traditions and so on. The nature is a rare and valuable product for urban tourists, the appropriate and calm environment to pass the leisure time and rest away from the conventional urban environment pollution. Participation in rural activities, mostly being present or coming along with villagers in rural customary production activities, sitting by the carpet weavers, milking the cows, farming, fruit picking and harvesting are considered of some examples.

Tourist's presence in the village and reviewing villager's activities in all the aforementioned items without participating but only to learn about them. Rural tourism needs to be considered as a sustainable form of tourism; because it is expected that presence of tourists help to improve the rural lifestyle, promoting their economical power, and preservation of rural environment and culture. This form of tourism can lead to preservation of traditions and ancient rural moral codes and transferring them into cities. Sometimes the sustainability of some rural regions is relied on the presence of tourists and their attention to such regions [6].

\section{Sustainable Development of Rural Tourism}

The attention to the sustainable tourism started in 1960 upon recognition of the mass tourism impact and other tourism activities impacts on economy, environment and culture in home tourism areas. The process started in 1970s by the appearance of green tourism concept based on which the value of natural capital and amount of losses and damages done on environment are estimated, and furthermore focused on preservation of natural and cultural resources and other tourism resources for the current and future generations. Following these attempts the term and concept of sustainable tourism came to life as the only way of saving the nature and human.

One of the basic strategies for developing rural areas is paying attention to the point that tourism sets rural environments free from loneliness and isolation and creates a balanced development in villages, because by affecting three aspects of economy, society and environment within the participation of rural communities in national economy development leads to a potential sustainable natural and environmental preservation and support. So it can be said that developing sustainable rural tourism is a process that insists on providing local community development needs, improving the supply chain, local production, encouraging local industry and professions, appropriate development with environmental and local society capacity and increase sustainable income of tourism. [14] 


\section{Tourism Capabilities in Yoush}

Yoush village is located in Mazandaran province, Nour town, Balade district and Shikh Fazl Allah Nouri village; Geographical width of 11 and 36 and geographical length of 43 and 51 and height of 2230 meters from sea level and south-west of Nour town.

The village is located between Central Alborz mountain range and surrounded by the mountains in four directions. The village was expanded in the direction of the springs and rivers and makes the village shine like a diamond from the highlands There is the $\mathrm{Oz}$ River in the southern areas of the village that feeds most gardens and farms in the village. The moderate slope in the main road made beautiful scenery of the village toward the highlands to the north, river and gardens in the south. Yoush is located in cold areas among the geographical distribution. The high height of the village in comparison to the sea level and its location among central Alborz Mountains created a unique climate for the village. The climate directly affected the architecture and stricture of the village and follows specific principles.

The weather condition and untouched nature of the region are still intact due to the tough paths and well-kept the rural structure and in the other hand the natural beauty of the mountains, river, unique scenery of the area calls out for anyone who is sick and tired of modern city life. The village is still home of the people who left there due to some issues, but come back during the summer and spring so that take the advantages of the natural and local beauty. Many of the people who had to leave the village and moved to cities, will return to the village to have fun and pass their leisure time and enjoy the natural bonus. [12]

Table 1. Yoush capabilities.

\begin{tabular}{ll}
\hline Natural capabilities \\
\hline - & Plant and animal diversity \\
- & Highlands and mountains \\
- & Roaring Oz river among the maze of the mountains \\
- & Red-spotted trout and other preserved species \\
- & Many animal species such as Kal- antelope, bear, panther, Quebec \\
- & Beautiful sceneries during the different seasons \\
- & Several springs \\
- & plants and aromatic herbs \\
- & beekeeping in the wilderness area \\
\hline
\end{tabular}

Table 2. Yoush Capabilities.

\begin{tabular}{l}
\hline Historical and cultural capabilities \\
\hline - \\
Nima Youshij's House and tomb, father of modern poetry and elegant \\
Bagh Shah house, belonging to the Naser Adin Shah periods, owned \\
by his women and made artistically by wood \\
- $\quad$ Neighborhood with Balade town and its historical castle \\
Traditional public bath belonging to the Safavi periods in the northern \\
parts of the village \\
Houses of Agha Reis and Abas Ali Khan made in Ghajar periods with \\
local architecture \\
Village location in Central Alborz Mountains, center of cultural and \\
historical importance
\end{tabular}

Table 3. Yoush Capabilities.

\begin{tabular}{ll}
\hline \multicolumn{2}{l}{ Religious capabilities - rituals and traditions } \\
\hline - & Ancient cemeteries, tomb of Kiadavoud, Ruh Al Amin temple \\
- & Yoush and Lale vey mosque with its unique architecture \\
- & Holding religious tragedy shows in 10 days in month of Moharam \\
- & $13^{\text {th }}$ day of Tir month holiday \\
\hline
\end{tabular}

Table 4. Yoush capabilities.

\begin{tabular}{ll}
\hline Physical Features \\
\hline - & Use of warm seats (korsi in Persian) in the winter by burning animal \\
wastes \\
- & Lots of sources of water \\
- & Comply with the topography of the area due to the sunlight radiation \\
angle & Frequency of canvas material produced in the village \\
passages with organic structure and different slope
\end{tabular}

\section{The Analysis of Strengths and Weaknesses in the Village of Yoush, Mazandaran}

Recovering the main affective factors on the resident areas growth process in city or village scale and determining the capabilities and limitations is only possible by correct recognition and objective analysis of the existing strengths, weakness, opportunities and threats. In the optimization project for the ancient structure of Yoush village, SWOT technique was used, in a way that strengths, weakness, opportunities and threats were reviewed and affective factors were recognized.

Here we tried to clearly reconsider the issues and problems of the village and opportunities and perspectives, so through recognition of the problems and issues in fields of geographical environment, social, cultural, economic and physical feature and achieve a solution. According to the full knowledge of the village in the first chapter, most important problems and issues can be outlined as the following:

1. Steep slope platform, type of soil, water and environment exposed to currents and floods and migration of the villagers are the most important factors of erosion and natural destruction of the village.

2. Keeping in mind those capabilities of everywhere, once act as a development factor that there might be a chance to be useful, Yoush valuable ancient structure, Oz river and stouts, gardens and highlands etc., with regard to the lack of facilities such as catering and residential spaces, toilets and organized spaces was not able to be an appropriate tourism sight.

3. Selling the lands around the village to outsiders and turning the pristine natural environments into residential spaces and villas.

4. Lack of police station in the village led to uncertainty and insecurity of village's social environment and the need for a police department is felt due to the increasing 
willingness to invest in the socio-cultural and economic sectors.

5. Lack of appropriate and secure employment opportunities in the village that made the rural youth migrate from there.

6. Forgetting customs and traditions ( $13^{\text {th }}$ day of Tir and etc.) hand craft (Shawl and carpet weaving) and lack of support for such activities

7. Lack of villagers small capital direction and creating cooperative investment of private and government sector

8. Abandoning the valuable structure and turning the important areas into wastelands

9. Lack of traffic signs on the road and specific paths around the village to guide tourist

10. Lack of open and public space in the rural new and valuable structure

11. Lack of appropriate rules and regulations for construction

12. Lack of parking space for the tourists vehicle

13. Lack of villagers awareness of architectural and physical values that attract tourists alongside the natural environment

14. Lack of compliance with health and environmental issues around the river and garden of the village; such problems are made by tourists which is for the lack of rest rooms and health care facilities is a factor that threats the promenade of the village

Here are some capabilities effective in developing the village:

1. Backgrounds of the tourism activities expansion in village and surrounding areas according to the characteristics of the natural environment and geography and climate are of the most important capabilities of the village in different seasons of Yoush. These capabilities are in forms of historical structures, $\mathrm{Oz}$ river, highlands of Alborz, green gardens and fruitful during the spring and summer, colorful fall in the village and etc. apart from those capabilities, coordination of human built structure and natural spaces with natural, climate and social needs of people are the other capabilities that are worth to be studied.

2. Access to the natural and historical road

Access to the Haraz main road from north, and Chalous-Tehran road from south and graveled road of the village makes trespassing to Yoush. Currently bus cooperatives of Shargh Terminal and private sectors of Tehran and Amol provide services to Yoush which is considerably reasonably priced and makes it good for people to travel. It takes 4 hours from Tehran and 2 hours from Amol to reach Yoush and equipped with promenade for tourists so that the village currently well prepared to host the tourists during the holidays and weekends. It is close to the populated city of Tehran and also Amol, Nour and Balade towns. Amol, Nour and Tehran are considered as the important urban areas close to Yoush and according to the near future and making of the Tehran-Nour freeway, natural spaces and environments like Yoush. The opportunity can be very effective in tourist attraction since people of the populated cities need calming and peaceful environments.

3. The availability of appropriate social and cultural atmosphere: development planning, reviewing social and cultural features to synchronize the plans and recommended projects with these features is one of the most important factors for development. There have been lots of projects and recommended plans that faced a dead end and social resistance in the aspect of economical development and failed. Therefore, the existence of an open cultural atmosphere and insight and people awareness about different issues in a higher level would help gravely in completion of those plans and projects.

People in Yoush due to its closeness to the Capital Tehran and some Mazandaran towns (Amol, Nour, Nowshahr) and seasonal migration of villagers to such cities and even some who went abroad, are well familiar with the cultural and social features of urban and more developed areas, so based on these features they know how to behave with tourists and have positive reaction.

4. Availability of cultural, historical study backgrounds; the historical structure of the village which is shaped due to the social and security conditions in the past is a research subject that in addition to architectural studies, one can study its historical, political conditions and dressing customs. In the other hand the old dialect of the villagers is another cultural research subject in the field of linguistics.

5. A lot of water sources and unfarmed grounds that are well enough to be turned into farms and fish breeding pools.

6. Infrastructures availability needed for development

7. Existence of various gypsum and lime mines and coal in rural area

8. Existence of valuable rural historical and architectural structure

9. Historical and religious elements availability such as Nima's House, Abas Ali Khan, Agha Reis, Kia Davood tomb, Seyed Ruh Adin tomb, Yoush mosque, Jame mosque, Lalevey mosque

10. The appropriate combinational existence of natural factors and human build elements and tourist attraction possibility according to the beauty of the village

11. Open space availability in the village and new structure and valuable structure to be physically designed.

12. The existence of native and local materials such as stone, soil, plaster trunks, optimal cellular, and straw for the reconstruction of buildings and valuable bodies

13. The existence of spaces under the ownership of the tourism and cultural heritage organization and the possibility of their use for the construction of a place of residence required or have fun. 


\section{Study and Review of Similar Sample}

\subsection{Khoushe Sar Ecotourism (Local Residential Places)}

A wise ecotourism is in a close relationship with employment network in a way that through organizing the regions in competitive cluster forms and focuses on benefits and unique features of every single one of them.

A competitive cluster is used to connect a group of strategic relationships between private and government sector participants under a unique support plan along with ecotourism development so that help, review and support improvement of the protected areas management.

The goal of the Khoushe Sar was area development and social organization. A luster is a factor made to network collaboration in order to public convenience and acts as a quality assurance system. A cluster works as a social collaborative network based on ecological values that not only include the members but also structural, organizational and service collaborations based on service factors. [11] according to the aforementioned factors about Khoushe Sar, here we talk about introducing Khoushe Sar and tourism in Iran. An active group in ecotourism that created the chance for the tourists to experience other nations lifestyles, made ecotourism possible for the rest of the world after starting an integrated network in Iran. The goal of the network was to create residential places which its architecture aligns with its environment. The drinks and foods are local; hand crafts are introduced, and sold. The visits are done in native ways (Camel riding, cycling, walking, and donkey riding) and even local and traditional games are done with tourists' participation. All the founding members were native people and still residing in their local houses. They have organically made a local network and had chosen a healthy life close to the nature in the traditional structure.

Important features of the group are: 1. selecting a native house refurbished and reside in it 2 . Traditional and cuisine food with local catering 3. The use of simple local interior design 4. Involving local residents in their activities 5. Respect for the local people culture and traditions 6 . The introduction of specific industries and arts in the area 7. Introducing Persian mystical music and its integration with world music

The result of a research related to Khoushe Sar villages and its effects showed that tourists participant in the villages in Khoushe Sar form, leads to higher quality of life of the local people. The villagers were happy about their presence and reduced the negative effects of tourism in such areas. [11]

In the following we will introduce and review one of the eminent villages in tourism equipped residential areas from Khoushe Sar ecotourism:

Atshouni domicile, Garme village, Iran central dessert:

The great central dessert of Iran is more than $100 \mathrm{sq} \mathrm{km}$ and the largest salt meadow. Its most valuable parts (salts and beautiful scenery and historical way of communication, etc) are located in Semnan province. [4] for years the desserts are taken into account as tourists attraction factors which includes one fifth of the earth and are of hottest spots of the world that is able to easily attract adventurous tourists. Garme village is one of those located in the central dessert of Iran and nowadays is considered as a tourism spot. The village annually attracts a lot of tourists from all over the world. Garme is located in 33.31 North degrees and 55.02 East degrees of Isfahan.[17]

The traditional house of Al Davood in Garme was turned into a guest house with 10 rooms by the sons of Maziar. Persian foods are cooked in the house and presented to the tourists. Camel riding is done on the way from Tabas to Mesr, a path that was discovered a century ago by the clan of $\mathrm{Al}$ Davood along with some Swedish tourists. The path was a part of the Silk Road. Camel riding on the long way of $50 \mathrm{~km}$ takes a half an hour. The name for the guest house was Atshouni and is recorded in the book of Lonely Planet. Spring and fall which are dessert seasons there will be about 100 tourists in the guest house and due to the high tourist demand, the hand craft industry of the local area is increasing.

\subsection{Reasons for Selecting the Village as a Sample}

Due to Yoush's several capabilities and its comparison with Khoushe Sar ecotourism in which lots of tourism activities and other related activities are done, the sample was chosen, also the environment was paid more attention to be built residential places. Smell of the soil, carved plaster painting on the walls, lumbers, the light and heat of fire, the taste of tea made on fire in the structure of Atshouni is full of intimacy that makes the place lovely.

\section{Suggested Solutions}

Here are some preliminaries that are possible only by the effective presence of the people, groups and local organizations and helps tourism in such villages in a sustainable form.

1. The establishment of the tourism and cultural heritage site in Yoush village

2. Identification, registration and research on the historic structure and valuable buildings

3. Advertising, raising awareness and introduction

4. Optimizing the river paths and river banks

5. Museum and catering

6. Organizing sightseeing sites in the village

7. Tourism services

8. Creating catering and staying places

9. Rebuilding and reviving Safavi's traditional bath, and turning it into a historical Yoush anthropology museum

10. Reconstruction and reviving of the religious places and historical mosque, Ruh Al Amin temple, and Kia Davod tomb for the tourists

11. Organizing Oz river banks

12. Creating a hunting and mountain climbing station

13. Creating hand craft market

14. Holding festivals and other related ceremonies to develop the village, and also literary and cultural seminars, like Nimalogy, Nima poem nights etc. any kind of investment on participation in valuable structure, encourages current residents, whether immigrant or new generations to be resided in the village. This would also 
lead to employment and moneymaking activities that attracts tourists and results in reviving of the village.

15. Registering the village as unique structures in List of national monuments.

16. Owning, reconstruction and reviving the houses next to Nima's as guest houses

17. Reviving of the unique places, changing their usability, and organizing spaces for valuable buildings

18. Organizing services such as garbage disposal, guidelines for tourist on the road, public toilets, building new structures for the tourists equipped with water, electricity and telephone.

19. Gardens reviving (Apple, pear, apricot etc.) and the possibility to direct water to the farming lands

20. Forming and boosting investment cooperative to revive village's hand craft industry

21. Encouraging the youth to stay in the village (employments)

22. Reviving or boosting the native language

23. Creating a relationship between three elements of river, mountains, and local structure and using the unique sceneries and emphasize on the river banks and equipping them with useful facilities.

\section{Discussion and Conclusion}

We are aware that rural tourism will only be successful and lead to positive results in the sustainable development upon the local people participation and presence, however by knowing Yoush village and its capabilities we can very well host tourists in the region local way.

The necessity of using great physical potentials in this area will result in creating a memorable, high quality and active location that may be effective in the lives of rural people and also presenting services to the tourists. The goal for choosing this topic was to better recognize Yoush's capabilities, which is Nima Youshijs birthplace. Because the correct recognition of the main effective factors on any places growth in the city or village scale and determining the limitations and capabilities is only possible by the correct and purposeful understanding of their strengths, threats, opportunities and weaknesses based on which a sustainable approach in development of the area as a cultural and tourism center appears.

\section{References}

[1] Al Ajal, David, 2010, sustainable tourism management a heritage for the future, translated by Hamid Reza Jafari and et al, Tehran publications

[2] Dibai, Parviz, 1993, Tourism understanding. Allame Tabatabai University publications, $\mathrm{p} 7$
[3] Kordovani, Parviz, 2008, Great salt meadow of central Iran and subsidiary regions, capabilities and solutions for income, Tehran university publications

[4] Mashhadizade, Dehaghani, 1995, an analysis on urban planning features in Iran, Elm o Sanat university publication

[5] Ranjbarian, Bahram and Zahedi, Mohamad, 2006, Toursim understanding, Chaharbagh publications of Isfahan

[6] Amini Faskhudi, Abbas (2011), an analysis on the State of the country's rural areas in cultural attitudes, Journal of peasant studies, volume 1, issue 3, pp. 82-53

[7] Izadi, mohammad saeed,2004, Development in the attitude: the necessity of the restoration approach to cultural wealth, the fourth year of a seven-City Journal number 12 and 13 .

[8] Shahidi, Mohamad Sharif and Zahra Alsadat Gudarzi Mohammad Mahdi Soroush (2010), evaluation of the impacts of tourism in rural areas of planning, the journal of the study of human geography, no. 67, pp. 113-99

[9] Tayebi, seyed Komeyl and Seyed Komeil Halibi- Amir Jabbari, Ruh Allah Babaki,Autumn 2008, the relationship between tourism and economic growth (case study of OECD countries plus Iran, and selected countries). The magazine and knowledge (scientific-research) year XV, no. 24

[10] Faraji Rad, Abdolreza and Ehsani Afsane, (2012), the impact of local home stay (placement of Starling canvas cluster) on the upgrading of local community life (with an emphasis on long slope and Garmeh village), Journal of geography of the land, scientific-research, year VIII, no. 30, pp. 77-63

[11] Fouladian, Yaser, Shafaee, Salma, 2013, reviews the potential for cultural tourism in the Eastern village of Yoush, Mazandaran, rustic look with a cluster index to history of Iran, the second largest canvas Starling National Conference on tourism and ecotourism, Hamedan, Iran

[12] Rahimi, Elnaz, 2013, Sustainablity in other words, (architecture after incident and humanitarian. A friendly chat with Pouya Khazaili , Parsa) the journal of architecture, no. 26, pp. 44-49

[13] Rokn Adin Eftekhari ,and Rokn Aldin Eftekhari, AbdolrezaDavod Mahdavi, Mahdi Poor Taheri,2011,The process of localization of rural tourism sustainable development indicators in the country, the rural research, issue 4 , winter 2011, pp. 1-41

[14] Dong, Junyan and Jin Hong, the design strategy of green rural housing of Tibetan areas in Yunnan, China, renewable Energy 49(2013)63-67.www.elsevier.com

[15] Rokn Adin Eftekhari, Abdolreza and Mahdavi (2006), rural tourism development strategies using the swot model: small Lavasan rural district www.sid.ir Geography Journal, No 2 Summer 1385 .

[16] www.irandeserts.com/garmeh.htm

[17] The General Census of the population and the statistics center of Iran, Iran's statistics Center, 1957 Publishing House to 1996. 